\title{
Radiographical efficacy of systemic treatment for bone metastasis from renal cell carcinoma
}

\author{
TAKAHITO NEGISHI $^{1}$, NOBUKI FURUBAYASHI ${ }^{1}$, DAI TAKAMATSU $^{1}$, KOUSUKE IEIRI $^{1}$, \\ NAOTAKA NISHIYAMA $^{2}$, HIROSHI KITAMURA ${ }^{2}$ and MOTONOBU NAKAMURA ${ }^{1}$ \\ ${ }^{1}$ Department of Urology, National Hospital Organization Kyushu Cancer Center, Fukuoka 811-1395; \\ ${ }^{2}$ Department of Urology, Graduate School of Medicine and Pharmaceutical Sciences \\ for Research University of Toyama, Toyama 930-0194, Japan
}

Received February 25, 2020; Accepted August 24, 2020

DOI: $10.3892 / \mathrm{ol} .2020 .12130$

\begin{abstract}
Enlarged bone metastasis from renal cell carcinoma (RCC) can cause skeletal-related events, and thus treatment to inhibit the growth of bone metastases is often required. Although radiotherapy for RCC bone metastases can achieve a certain degree of local control, evidence is lacking regarding the effects of systemic therapy to improve bone metastasis. The present study aimed to assess the treatment efficacy of targeted therapy and immune checkpoint inhibitors, and to determine whether systemic therapy without radiotherapy can shrink bone metastases of RCC. The present study retrospectively reviewed 44 patients with RCC with bone metastases treated via systemic therapy, including targeted therapy or immune checkpoint inhibitors. Patients were divided into two groups: Those who underwent systemic therapy with radiotherapy for bone lesions $(n=29)$; and those who underwent systemic therapy without radiotherapy for bone lesions $(n=15)$. The radiographical efficacy of systemic therapy and the time to progression of bone metastases were compared between groups. The overall response rate of systemic therapy with radiotherapy was $44 \%$, and in total, 13 patients demonstrated a partial response. Only one patient $(6 \%)$ had a partial response among those who were treated via systemic therapy without radiotherapy. The time to progression of bone metastasis was 9.5 and 2.1 months in patients treated with and without radiotherapy, respectively $(\mathrm{P}<0.0001)$. Collectively, the present results suggested that targeted therapy or immune checkpoint inhibitors without radiotherapy had only a slight effect on bone metastasis control.
\end{abstract}

Correspondence to: Dr Takahito Negishi, Department of Urology, National Hospital Organization Kyushu Cancer Center, Notame 3-1-1 Minami-ku, Fukuoka 811-1395, Japan

E-mail: negishi-takahito@umin.ac.jp

Key words: renal cell carcinoma, bone metastasis, systemic treatment, radiographical efficacy, skeletal-related event

\section{Introduction}

More than 250,000 new cases of renal cell carcinoma (RCC) are diagnosed annually and 116,000 patients die from the disease worldwide. (1). A total of $25-30 \%$ of newly diagnosed renal RCC cases present with metastases (2), and $20-40 \%$ of patients with locally limited RCC undergo relapse during the follow-up period, even if the tumors are surgically resected (3). Moreover, with regards to metastatic RCC, $30 \%$ of patients have bone metastasis (4).

Bone metastasis from RCC is mainly osteolytic, decreasing bone integrity and causing skeletal-related events (SREs) (5), including pathologic fractures and the need for radiotherapy for bone pain, as well as surgical interventions to treat or prevent an impending fracture, spinal cord and nerve root compressions, and hypercalcemia (5). It has been reported that $>70 \%$ of patients with RCC with bone metastases experience $\geq 1$ SRE during their clinical course (5), and subsequently experience a decrease in their quality of life (QOL) (6).

The size of bone metastatic lesions is a risk factor for pathological fractures (7), and an enlarged bone metastasis in the vertebral body may induce spinal cord and nerve root compression (8). Bulky bone metastasis can cause SREs, and thus treatment to decrease or inhibit the growth of bone metastases is often required (9). Although radiotherapy for RCC bone metastases can achieve a certain degree of local control (10), there is not sufficient evidence regarding the effects of systemic therapy to improve bone metastasis.

Targeted therapy and immune checkpoint inhibitors have been reported to prolong either the progression-free or overall survival time of patients with metastatic RCC based on the results of clinical trials. However, fewer patients with bone metastases are included in these trials compared with patients with lung or lymph node metastases (11-14), as bone lesions are considered difficult to evaluate by the Response Evaluation Criteria in Solid Tumors (RECIST) criteria (15), and the frequency of bone metastases is lower compared with that of lung or lymph node metastases in RCC (4). Therefore, the effect of targeted therapy and immune checkpoint inhibitors on bone lesions remains unknown, and which agents should be administered to patients with bone dominant metastatic RCC is yet to be fully elucidated. 
Several methods for evaluating the treatment efficacy for bone lesions have been suggested $(16,17)$. For example, Hamaoka et al (17) proposed the MD Anderson bone response criteria, in which not only a size reduction, but also osteoblastic changes are considered evidence of treatment efficacy for bone lesions. These criteria were originally developed for bone metastases from breast cancer, but have been adopted during a clinical trial evaluating the efficacy of radium-223 dichloride for RCC bone metastasis (18).

The present study aimed to evaluate the treatment efficacy of targeted therapy and immune checkpoint inhibitors using the MD Anderson bone response criteria, to examine whether systemic therapy itself can shrink bone metastases of RCC.

\section{Patients and methods}

Enrollment of patients. The present study retrospectively reviewed 44 patients ( 32 men and 12 women) with RCC with bone metastases, who were treated with systemic therapy at the National Hospital Organization Kyushu Cancer Center and Graduate School of Medicine and Pharmaceutical Sciences for Research University of Toyama between October 2008 and March 2020. The median age at diagnosis of bone metastasis was 66 years (age range, 39-83 years). Key inclusion criteria were: Measurable bone metastasis on CT (diameter, $>1.0 \mathrm{~cm}$ ); and systemic therapy after a diagnosis of bone metastasis. Key exclusion criteria were: Bone metastasis that could not be detected on CT; and the absence of systemic therapy after a diagnosis of bone metastasis. The present study was approved by the Institutional Review Board of the National Hospital Organization Kyushu Cancer Center.

Evaluation of patient data. Patients were divided into two groups: Those who underwent systemic therapy with concomitant or sequential radiotherapy for bone lesions $(n=29)$; and those who underwent systemic therapy without radiotherapy for bone lesions $(n=15)$. The radiographical efficacy of systemic therapy was evaluated according to the MD Anderson bone response criteria, which was previously reported (Data S1) (17). The time to progression of bone metastases and bone-specific overall response rate were calculated and compared between groups. The starting point for the analysis was set as the date of the initiation of systemic treatment after the diagnosis of bone metastasis from RCC.

Radiotherapy for bone metastasis was performed using a multidisciplinary conference consisting of medical oncologists, orthopedic surgeons, radiation oncologists and urologists (9). Bone metastases, which can cause pathological fracture and cord compression (19), were an indication for radiotherapy to prevent SRE, even when patients did not have ostealgia. Patients with ostealgia were suggested for radiotherapy to relieve pain. The dose of palliative radiotherapy was 30-40 Gy. In the present study, only one patient with solitary bone metastasis, without other organ metastasis, underwent curative radiotherapy at a dose of $50 \mathrm{~Gy}$. The other patients underwent palliative radiotherapy.

Statistical analysis. Background characteristics of the groups were compared using the $\chi^{2}$ test or Fisher's exact test, and unpaired Student's t-test for continuous variables. The Kaplan-Meier method was used to estimate the time to the progression of bone metastases with systemic therapy. A log-rank test was used to compare the time to progression between the groups. A Cox proportional hazards model was used to evaluate the predictors of the time to progression in univariable and multivariable analyses. $\mathrm{P}<0.05$ was considered to indicate a statistically significant difference. All analyses were performed using the $\mathrm{JMP}^{\circledR}$ Pro software package (version 14.2.0; SAS Institute, Inc.).

\section{Results}

Patient characteristics. The characteristics of the 44 patients are presented in Table I. In total, 29 patients underwent radiotherapy for bone lesions, and 15 did not undergo radiotherapy. More patients received bone-modifying agents (BMA) in the group with radiotherapy compared with the group without radiotherapy $(\mathrm{P}=0.021)$. The median follow-up period was 13.2 months (range, 0.7-86.0 months), and the median radiation dose delivered to the bone lesions was $30 \mathrm{~Gy}$ (range, 30-50 Gy). A total of $22(50 \%)$ patients had bone metastases when they were diagnosed with RCC, and 25 (57\%) had multiple bone metastases when they were diagnosed with bone metastasis. Regarding systemic therapy after the diagnosis of bone metastasis, targeted therapy and immune checkpoint inhibitors were administered to $36(82 \%)$ and $8(18 \%)$ patients, respectively.

Treatment efficacy. The overall response rate of systemic therapy with radiotherapy was $44 \%$ in the present study; in total, 13 patients demonstrated a partial response, including 12 patients and one patient administered targeted therapy and immune checkpoint inhibitors, respectively. Only one patient $(6 \%)$ had a partial response among those who did not undergo radiotherapy (Table II).

The time to progression of bone metastasis was 9.5 and 2.1 months in patients treated with and without radiotherapy, respectively $(\mathrm{P}<0.0001 ;$ Fig. 1).

Cox proportional hazards model. A Cox proportional hazards model identified that a systemic therapy regimen, BMA and International Metastatic RCC Database Consortium risk stratification were not associated with the time to progression. However, systemic therapy with radiotherapy was a predictive factor of the time to progression of bone metastasis (hazard ratio, 16.60; 95\% CI, 4.53-60.90; $\mathrm{P}<0.0001$; Table III).

Skeletal-related events. The details of the initial SREs experienced by patients are presented in Table IV. A total of 36/44 patients experienced SREs, with the most commonly being the requirement for radiotherapy for bone pain. Moreover, $6 / 15$ patients who underwent systemic therapy without radiotherapy, received radiotherapy for bone metastases due to pain after the failure of systemic therapy.

\section{Discussion}

Bone metastasis is a poor prognostic factor for metastatic RCC $(20,21)$, and it can worsen despite the administration of systemic chemotherapy, even when it is effective for metastases in other organs. Enlarged bone lesions cause SRE, decrease the QOL and result in a poor prognosis $(5,6)$; thus, it is important to control 
Table I. Characteristics of the patients $(n=44)$ with radiotherapy for bone metastasis $(n=29)$ or without radiotherapy $(n=15)$.

\begin{tabular}{|c|c|c|c|c|}
\hline Variable & All patients & $\begin{array}{l}\text { Radiotherapy for } \\
\text { bone metastasis }\end{array}$ & $\begin{array}{l}\text { No radiotherapy for } \\
\text { bone metastasis }\end{array}$ & P-value \\
\hline Age at diagnosis of bone metastasis, years & $66(39-83)$ & $65(39-83)$ & $63(43-76)$ & 0.911 \\
\hline \multicolumn{5}{|l|}{ Sex } \\
\hline Male & $32(73)$ & $22(76)$ & $10(66)$ & \multirow[t]{2}{*}{1.000} \\
\hline Female & $12(27)$ & $7(24)$ & $5(34)$ & \\
\hline \multicolumn{5}{|l|}{ IMDC risk stratification } \\
\hline Favorable & $11(25)$ & $7(24)$ & $4(27)$ & \multirow[t]{3}{*}{0.854} \\
\hline Intermediate & $23(52)$ & $16(55)$ & $7(46)$ & \\
\hline Poor & $10(23)$ & $6(21)$ & $4(27)$ & \\
\hline \multicolumn{5}{|l|}{ Histology } \\
\hline Clear cell & $37(84)$ & $24(83)$ & $13(86)$ & \multirow[t]{2}{*}{1.000} \\
\hline Non-clear cell & $7(16)$ & $5(17)$ & $2(14)$ & \\
\hline \multicolumn{5}{|l|}{ Nephrectomy } \\
\hline Yes & $36(82)$ & $25(86)$ & $11(73)$ & \multirow[t]{2}{*}{0.414} \\
\hline No & $8(18)$ & $4(14)$ & $4(27)$ & \\
\hline \multicolumn{5}{|l|}{ Metastasis at the diagnosis of RCC } \\
\hline Bone metastasis with or without extraosseous metastasis & $22(50)$ & $15(52)$ & $7(46)$ & \multirow[t]{3}{*}{0.935} \\
\hline Extraosseous metastasis only & $6(14)$ & $4(14)$ & $2(14)$ & \\
\hline No metastasis & $16(36)$ & $10(34)$ & $6(40)$ & \\
\hline \multicolumn{5}{|l|}{ Multiplicity of bone metastasis } \\
\hline Solitary & $19(43)$ & $12(41)$ & $7(46)$ & \multirow[t]{2}{*}{0.737} \\
\hline Multiple & $25(57)$ & $17(59)$ & $8(54)$ & \\
\hline \multicolumn{5}{|l|}{ Bone-modifying agents } \\
\hline Yes & $17(39)$ & $15(52)$ & $2(14)$ & \multirow[t]{2}{*}{0.021} \\
\hline No & $27(61)$ & $14(48)$ & $13(86)$ & \\
\hline \multicolumn{5}{|l|}{ Systemic therapy after diagnosis of bone metastasis } \\
\hline Sunitinib & $24(56)$ & $14(48)$ & $10(66)$ & \multirow[t]{8}{*}{0.110} \\
\hline Axitinib & $3(7)$ & 1 (4) & $2(14)$ & \\
\hline Pazopanib & $3(7)$ & $3(10)$ & 0 & \\
\hline Sorafenib & $2(4)$ & $2(7)$ & 0 & \\
\hline Temsirolimus & $2(4)$ & $2(7)$ & 0 & \\
\hline Everolimus & $2(4)$ & 0 & $2(14)$ & \\
\hline Nivolumab & 4 (9) & $3(10)$ & $1(6)$ & \\
\hline Nivolumab, Ipilimumab & 4 (9) & $4(14)$ & 0 & \\
\hline
\end{tabular}

Data are presented as the median (interquartile range) or a n (\%). RCC, renal cell carcinoma; IMDC, International Metastatic Renal Cell Carcinoma Database Consortium.

Table II. Overall response rate of systemic therapy with $(n=29)$ or without radiotherapy $(n=15)$.

\begin{tabular}{lrr}
\hline Best response, $\mathrm{n}(\%)$ & Systemic therapy with radiotherapy & Systemic therapy without radiotherapy \\
\hline Partial response & $13(44)$ & 1 (6) \\
Stable disease & $4(14)$ & 0 \\
Progressive disease & $11(38)$ & $11(74)$ \\
Non-evaluable & $1(4)$ & $3(20)$ \\
\hline
\end{tabular}

bone lesions in order to avoid these outcomes. However, while improved efficacy of radiotherapy and surgery for controlling bone lesions has been reported $(10,22)$, whether systemic therapy itself can control bone lesions remains unknown. 
Table III. Univariate and multivariate analyses to evaluate the predictors of the time to progression of bone metastasis.

\begin{tabular}{|c|c|c|c|c|c|}
\hline & & $\begin{array}{l}\text { Univariate } \\
\text { analysis }\end{array}$ & & $\begin{array}{l}\text { Multivariate } \\
\text { analysis }\end{array}$ & \\
\hline Variable & $\mathrm{n}$ & HR $(95 \%$ CI $)$ & P-value & HR (95\%CI) & P-value \\
\hline \multicolumn{6}{|l|}{ IMDC risk stratification } \\
\hline Favorable & 11 & 1 (reference) & & 1 (reference) & \\
\hline Intermediate & 23 & $1.88(0.66-5.33)$ & 0.234 & $1.79(0.55-5.90)$ & 0.336 \\
\hline Poor & 10 & $1.47(0.45-4.82)$ & 0.527 & $1.24(0.36-4.21)$ & 0.735 \\
\hline \multicolumn{6}{|l|}{ Bone-modifying agents } \\
\hline Yes & 17 & 1 (reference) & & 1 (reference) & \\
\hline No & 27 & $3.07(1.28-7.38)$ & 0.012 & $1.45(0.53-4.00)$ & 0.473 \\
\hline \multicolumn{6}{|l|}{ Systemic therapy } \\
\hline With radiotherapy & 29 & 1 (reference) & & 1 (reference) & \\
\hline Without radiotherapy & 15 & $12.62(4.17-38.25)$ & $<0.0001$ & $16.60(4.53-60.90)$ & $<0.0001$ \\
\hline \multicolumn{6}{|c|}{$\begin{array}{l}\text { Systemic therapy regimen after diagnosis } \\
\text { of bone metastasis }\end{array}$} \\
\hline Targeted therapy & 36 & 1 (reference) & & 1 (reference) & \\
\hline Immune checkpoint inhibitor & 8 & $2.17(0.84-5.59)$ & 0.108 & $2.88(0.88-9.43)$ & 0.080 \\
\hline
\end{tabular}

IMDC, International Metastatic Renal Cell Carcinoma Database Consortium; HR, hazard ratio.

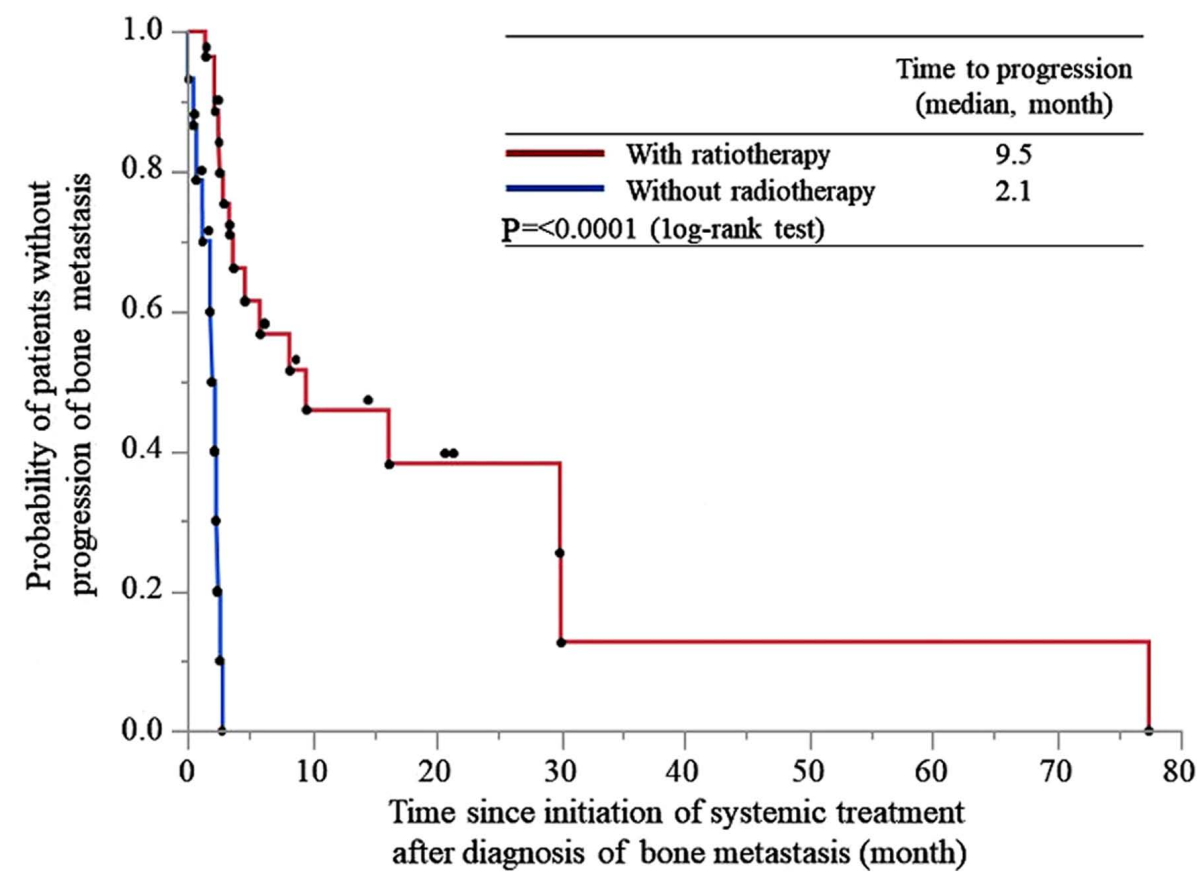

Figure 1. Time to progression of bone metastasis from the initiation of systemic treatment after the diagnosis of bone metastasis in patients treated with and without radiotherapy.

Despite a number of reports having been published discussing the prognosis of patients with RCC with bone metastases, to the best of our knowledge, these have not mention the overall response rate of targeted therapy or immune checkpoint inhibitors for bone lesions $(22,23)$. Bone lesions are difficult to measure accurately or evaluate via the RECIST criteria. Therefore, the present study adopted the
MD Anderson bone response criteria, which can be used to evaluate the treatment efficacy for bone lesions by considering the size and sclerotic changes (17). While these criteria were originally developed for evaluating bone metastases from breast cancer, they have been used in translational research to evaluate the effect of radium-223 dichloride combined with targeting therapy on bone metastases of RCC (18). 
Table IV. Details of the initial skeletal-related events experienced by patients $(n=36)$ treated with systemic therapy with $(n=27)$ or without $(\mathrm{n}=9)$ radiotherapy.

\begin{tabular}{lccc}
\hline Skeletal-related events, $\mathrm{n}(\%)$ & $\begin{array}{c}\text { Total no. patients } \\
\text { Total no. patients }\end{array}$ & $\begin{array}{c}\text { Systemic therapy } \\
\text { with radiotherapy }\end{array}$ & $\begin{array}{c}\text { Systemic therapy } \\
\text { without radiotherapy }\end{array}$ \\
\hline Need for radiotherapy for bone pain & $30(83)$ & $24(89)$ & $6(67)$ \\
Spinal cord and nerve root compression & $3(8)$ & $3(11)$ & 0 \\
Hypercalcemia & $2(6)$ & 0 & 0 \\
Pathologic fracture & $1(3)$ & 0 & 0 \\
Surgical interventions & 0 & $(22)$ \\
\hline
\end{tabular}

Bone metastases in RCC are mainly osteolytic in nature and decrease the bone integrity, induce bone pain and result in significant morbidity for patients due to associated SREs (24). Osteoclast activation due to the presence of malignant cells leads to bone destruction (9), and a decline in malignant cells as a result of treatment can decrease osteoclast activity and induce sclerotic changes. It is therefore reasonable to regard sclerotic changes as indicating treatment efficacy.

The present results suggested that targeted therapy or immune checkpoint inhibitor without radiotherapy had only a slight effect on bone metastasis control. With regards to targeted therapy, a beneficial effect of cabozantinib, which is not available in Japan, on bone metastasis has been reported in a previous clinical trial, but the overall response rate was not mentioned, and how bone lesions are altered by cabozantinib is yet to be elucidated (25). By contrast, the results of the present study demonstrated that systemic therapy with sequential or concomitant radiotherapy exhibited a significant impact on bone metastasis control and prolonged the time to progression. This suggests a synergic effect of radiotherapy combined with targeted therapy or immune checkpoint inhibitors $(26,27)$. Targeted therapy or immune checkpoint inhibitors can enhance radiosensitization and improve local control, but the optimal timing and schedule remain unknown $(26,27)$. Surgical resection is promising for controlling bone lesions (9); however, in a clinical setting, numerous cases are unresectable due to a poor physical condition or unfavorable location of the bone lesion, among other reasons (28). For such cases, targeted therapy or immune checkpoint inhibitor therapy alone is not adequate, and radiotherapy should be considered to maintain the QOL.

Several limitations associated with the present study should be discussed. For example, this was a retrospective study that contained a relatively small sample size and a heterogeneous group of patients. However, the current data reflected the clinical practice and demonstrated a radiographically overall response rate specialized for bone lesions. To the best of our knowledge, the present findings have not been previously reported and may be useful for treating patients with RCC with bone metastases.

In conclusion, almost none of the patients who received systemic therapy without radiotherapy achieved a response in bone metastasis from RCC. Systemic therapy with radiotherapy exhibited a significant impact on bone metastasis control; however, it is still not adequate. Bone metastasis from RCC remains challenging to manage, despite multimodal therapy. Radium-223 dichloride, an $\alpha$-emitting therapy that induces DNA double-strand breaks leading to cellular death in areas with increased osteoblastic activity, is reported to be effective when combined with targeted therapy for controlling RCC bone metastasis (15). Moreover, novel approaches for treating RCC bone metastasis are expected to be developed.

\section{Acknowledgements}

The authors would like to thank Dr Inoue and Dr Kumagai (National Hospital Organization Kyushu Cancer Center, Fukuoka, Japan) for analyzing the samples.

\section{Funding}

No funding was received.

\section{Availability of data and materials}

The datasets used and/or analyzed during the present study are available from the corresponding author upon reasonable request.

\section{Authors' contributions}

TN conceived and designed the analysis. All authors acquired the data. TN and NF analyzed the data. TN and NF drafted the manuscript. DT, KI, NN, HK and MN acquired the data, assisted with statistical analysis, supervised the study and revised the manuscript critically for important intellectual content. All authors read and approved the final manuscript.

\section{Ethics approval and consent to participate}

The present study was approved by the Institutional Review Board of National Hospital Organization Kyushu Cancer Center (Fukuoka, Japan; approval no. 2014-99) and the Graduate School of Medicine and Pharmaceutical Sciences for Research University of Toyama (Toyama, Japan; approval no. RCOI2019133). Written informed consent was provided by all patients prior to the study start.

\section{Patient consent for publication}

Not applicable.

\section{Competing interests}

The authors declare that they have no competing interests. 


\section{References}

1. Ljungberg B, Campbell SC, Cho HY, Jacqmin D, Lee JE, Weikert S and Kiemeney LA: The epidemiology of renal cell carcinoma. Eur Urol 60: 615-621, 2011.

2. Gupta K, Miller JD, Li JZ, Russell MW and Charbonneau C: Epidemiologic and socioeconomic burden of metastatic renal cell carcinoma (mRCC): A literature review. Cancer Treat Rev 34: 193-205, 2008.

3. Du YJ, Pahernik S, Hadaschik B, Teber D, Duensing S, Jäger D, Hohenfellner M and Grüllich C: Survival and prognostic factors of patients with renal cell cancer with bone metastasis in the era of targeted therapy: A single-institution analysis. Urol Oncol 34: 433.e1-e8, 2016.

4. Bianchi M, Sun M, Jeldres C, Shariat SF, Trinh QD, Briganti A, Tian Z, Schmitges J, Graefen M, Perrotte P, et al: Distribution of metastatic sites in renal cell carcinoma: A population-based analysis. Ann Oncol 23: 973-980, 2012.

5. Santini D, Procopio G, Porta C, Ibrahim T, Barni S, Mazzara C, Fontana A, Berruti A, Berardi R, Vincenzi B, et al: Natural history of malignant bone disease in renal cancer: Final results of an Italian bone metastasis survey. PLoS One 8: e83026, 2013.

6 . Kinnane N: Burden of bone disease. Eur J Oncol Nurs (11 Suppl 2): S28-S31, 2007.

7. Mirels H: Metastatic disease in long bones: A proposed scoring system for diagnosing impending pathologic fractures. 1989 Clin Orthop Relat Res (415 Suppl): S4-S13, 2003.

8. Ruppert LM: Malignant spinal cord compression: Adapting conventional rehabilitation approaches. Phys Med Rehabil Clin N Am 28: 101-114, 2017.

9. Umer M, Mohib Y, Atif M and Nazim M: Skeletal metastasis in renal cell carcinoma: A review. Ann Med Surg (Lond) 27: 9-16, 2018.

10. Taunk NK, Spratt DE, Bilsky M and Yamada Y: Spine radiosurgery in the management of renal cell carcinoma metastases. J Natl Compr Cancer Netw 13: 801-809, 2015.

11. Motzer RJ, Hutson TE, Cella D, Reeves J, Hawkins R, Guo J, Nathan P, Staehler M, de Souza P, Merchan JR, et al: Pazopanib versus sunitinib in metastatic renal-cell carcinoma. $\mathrm{N}$ Engl J Med 369: 722-731, 2013.

12. Motzer RJ, Hutson TE, Tomczak P, Michaelson D, Bukowski RM, Rixe O, Oudard S, Negrier S, Szczylik C, Kim ST, et al: Sunitinib versus interferon alfa in metastatic renal-cell carcinoma. $\mathrm{N}$ Engl J Med 356: 115-124, 2007.

13. Motzer RJ, Escudier B, McDermott DF, George S, Hammers HJ, Srinivas S, Tykodi SS, Sosman JA, Procopio G, Plimack ER, et al: Nivolumab versus everolimus in advanced renal-cell carcinoma. N Engl J Med 373: 1803-1813, 2015.

14. Motzer RJ, Tannir NM, McDermott DF, Arén Frontera O, Melichar B, Choueiri TK, Plimack ER, Barthélémy P, Porta C, George $\mathrm{S}$, et al: Nivolumab plus ipilimumab versus sunitinib in advanced renal-cell carcinoma. N Engl J Med 378: 1277-1290, 2018.

15. Eisenhauer EA, Therasse P, Bogaerts J, Schwartz LH, Sargent D, Ford R, Dancey J, Arbuck S, Gwyther S, Mooney M, et al: New response evaluation criteria in solid tumours: Revised RECIST guideline (version 1.1). Eur J Cancer 45: 228-247, 2009.

16. Woolf DK, Padhani AR and Makris A: Assessing response to treatment of bone metastases from breast cancer: What should be the standard of care? Ann Oncol 26: 1048-1057, 2015.
17. Hamaoka T, Madewell JE, Podoloff DA, Hortobagyi GN and Ueno NT: Bone imaging in metastatic breast cancer. J Clin Oncol 22: 2942-2953, 2004

18. McKay RR, Bossé D, Gray KP, Michaelson MD, Krajewski K, Jacene HA, Walsh M, Bellmunt J, Pomerantz M, Harshman LC and Choueiri TK: Radium-223 dichloride in combination with vascular endothelial growth factor-targeting therapy in advanced renal cell carcinoma with bone metastases. Clin Cancer Res 24: 4081-4088, 2018.

19. Jehn CF, Diel IJ, Overkamp F, Kurth A, Schaefer R, Miller K and Lüftner D: Management of metastatic bone disease algorithms for diagnostics and treatment. Anticancer Res 36: 2631-2637, 2016.

20. Motzer RJ, Escudier B, Bukowski R, Rini BI, Hutson TE, Barrios CH, Lin X, Fly K, Matczak E and Gore ME: Prognostic factors for survival in 1059 patients treated with sunitinib for metastatic renal cell carcinoma. Br J Cancer 108: 2470-2477, 2013.

21. Motzer RJ,Escudier B, Oudard S, Hutson TE, Porta C, Bracarda S, Grünwald V, Thompson JA, Figlin RA, Hollaender N, et al: Phase 3 trial of everolimus for metastatic renal cell carcinoma: Final results and analysis of prognostic factors. Cancer 116: 4256-4265, 2010

22. Kitamura H, Takahashi A, Takei F, Hotta H, Miyano N, Shindo T, Igarashi M, Tachiki H, Kunishima Y, Muranaka T, et al: Molecular-targeted therapy and surgery may prolong survival of renal cell carcinoma patients with bone metastasis: A multi-institutional retrospective study in Japan. Anticancer Res 36: 5531-5536, 2016

23. Ruatta F, Derosa L, Escudier B, Colomba E, Guida A, Baciarello G, Loriot Y, Fizazi K and Albiges L: Prognosis of renal cell carcinoma with bone metastases: Experience from a large cancer centre. Eur J Cancer 107: 79-85, 2019.

24. Zekri J, Ahmed N, Coleman RE and Hancock BW: The skeletal metastatic complications of renal cell carcinoma. Int J Oncol 19: 379-382, 2001.

25. Choueiri TK, Escudier B, Powles T, Tannir NM, Mainwaring PN, Rini BI, Hammers HJ, Donskov F, Roth BJ, Peltola K, et al: Cabozantinib versus everolimus in advanced renal cell carcinoma (METEOR): Final results from a randomised, open-label, phase 3 trial. Lancet Oncol 17: 917-927, 2016.

26. Morris ZS and Harari PM: Interaction of radiation therapy with molecular targeted agents. J Clin Oncol 32: 2886-2893, 2014.

27. Sharabi AB, Lim M, DeWeese TL and Drake CG: Radiation and checkpoint blockade immunotherapy: Radiosensitisation and potential mechanisms of synergy. Lancet Oncol 16: e498-e509, 2015.

28. Tokuhashi Y, Matsuzaki H, Oda H, Oshima M and Ryu J: A revised scoring system for preoperative evaluation of metastatic spine tumor prognosis. Spine (Phila Pa 1976) 30: 2186-2191, 2005.

This work is licensed under a Creative Commons Attribution-NonCommercial-NoDerivatives 4.0 International (CC BY-NC-ND 4.0) License. 